\title{
Echinococcus multilocularis (Cestoda, Taeniidae) in Red foxes (Vulpes vulpes) in northern Belgium
}

\author{
M. Vervaeke ${ }^{\mathrm{a}, *}$, P. Dorny ${ }^{\mathrm{b}}$, F. Vercammen ${ }^{\mathrm{b}}, \mathrm{S}$. Geerts ${ }^{\mathrm{b}}$, J. Brandt $^{\mathrm{b}}$, \\ K. Van Den Berge ${ }^{\mathrm{c}}, \mathrm{R}$. Verhagen ${ }^{\mathrm{a}}$ \\ ${ }^{a}$ Department of Biology, University of Antwerp, Groenenborgerlaan 171, B-2020 Antwerp, Belgium \\ b Department of Animal Health, Institute of Tropical Medicine, Nationalestraat 155, B-2000 Antwerp, Belgium \\ ${ }^{\mathrm{c}}$ Institute for Forestry and Game Management, Gaverstraat 4, B-9500 Geraardsbergen, Belgium
}

Received 3 December 2002; received in revised form 17 April 2003; accepted 7 May 2003

\begin{abstract}
The first record of the tapeworm Echinococcus multilocularis (Cestoda, Taeniidae) in Red foxes (Vulpes vulpes) in northern Belgium is described. Between 1996 and 1999, 237 dead foxes were examined for the presence of this tapeworm using the intestinal scraping technique. Four foxes $(1.7 \%)$ were found to be infected with $E$. multilocularis and showed medium to very high parasitic burdens. Three infected foxes originated from the south of the study area and the fourth animal came from the north of the study area near the border with The Netherlands. These findings are discussed in relation to the high endemicity of E. multilocularis in southern Belgium and to the increased distribution of the Red fox ( $V$. vulpes) in northern Belgium during the last two decades. (C) 2003 Elsevier B.V. All rights reserved.
\end{abstract}

Keywords: Echinococcus multilocularis; Vulpes vulpes; Alveolar echinococcosis; Epidemiology; Belgium

\section{Introduction}

Echinococcus multilocularis is a small endoparasitic tapeworm belonging to the family of the Taeniidae (Eckert et al., 2001; Thompson and Lymbery, 1995). The typical life cycle is sylvatic with foxes (genera Vulpes and Alopex) and coyotes (Canis latrans) as final hosts, and rodents, particularly those of the family Arvicolidae, as intermediate hosts. Less frequently other species of the families Canidae and Felidae are final hosts, including the

\footnotetext{
* Corresponding author. Tel.: +32-3-2180469; fax: +32-3-2180474.

E-mail address: muriel.vervaeke@ua.ac.be (M. Vervaeke).
} 
domestic $\operatorname{dog}$ (Canis lupus f. familiaris) and domestic cat (Felis sylvestris f. catus) (Petavy et al., 1991, 2000; Eckert et al., 2001).

The presence of E. multilocularis does not seem to cause major symptoms to its final host, in contrast to the infection with metacestodes in intermediate and aberrant hosts that may cause severe and lethal disease. Humans are an aberrant host that may become infected by ingesting or inhaling eggs. After infection the metacestode stage develops. This is characterised by an infiltrative and destructive growth of the larval stage causing serious disease, i.e. alveolar echinococcosis, which is usually fatal. Alveolar echinococcosis is not only one of the most dangerous autochthonous parasitic zoonosis in central Europe, but also one of the most costly to treat (Eckert et al., 2000, 2001; Thompson and Lymbery, 1995).

E. multilocularis is widely distributed in the northern hemisphere where it is endemic in several regions in central Europe, most of northern and central Eurasia and parts of north America (Eckert et al., 2001). In central Europe the known geographic range of the parasite includes regions in Austria, Switzerland, France, Germany, Liechtenstein, Luxembourg, Belgium, The Netherlands, Poland, Czech Republic, Slovak Republic, Denmark, and the Norwegian Islands of Svalbard (Eckert et al., 2000, 2001; van der Giessen and Borgsteede, 2002; van der Giessen et al., 1999, 2001; Dubinsky et al., 1999; Kolarova, 1999; Romig et al., 1999; Tackmann et al., 1998; Losson et al., 1997; Eskens, 1997; Kolarova et al., 1996; Lucius and Bilger, 1995; Brochier et al., 1992).

The first record of E. multilocularis in Belgium was reported by Brochier et al. (1992), who found a $15.3 \%(13 / 85)$ prevalence in Red foxes in southeastern Belgium (i.e. the province of Luxembourg, a hilly region with a maximum altitude of $700 \mathrm{~m}$ above sea level). In 1997, Losson et al. reported a 51.0\% (74/145) prevalence of E. multilocularis in Red foxes in the same area, and in 2002 the presence of this tapeworm was detected for the first time in other regions in Wallonia (B. Losson and B. Brochier, pers. comm.). In 2002, the first human autochthonous case of alveolar echinococcosis was described in Belgium (Delbecque et al., 2002) and since 1999 (Y. Carlier, pers. comm.) six human cases of multilocular echinococcosis have been diagnosed in Belgium, the infection being most probably acquired locally.

Because of the lack of historical information on the occurrence of this parasite in Belgium, it is impossible to determine whether these records reflect a recent range extension of the parasite, or whether its presence had not been detected. For northern Belgium there are no previous data available on the occurrence of this tapeworm.

The aim of this study was to determine if E. multilocularis could be found in Red foxes in northern Belgium, given its presence in the south of the country and in the neighbouring countries Germany, France and The Netherlands. The results are discussed in relation to the increase in numbers and distribution of the Red fox (Vulpes vulpes) in northern Belgium during the last two decades.

\section{Material and methods}

Between 1996 and 1999, 237 foxes were collected as hunting and road casualties in northern Belgium. The animals were individually labelled with an identification number and information about the exact locality, date and cause of death. The carcasses were transported 
in sealed plastic bags and were stored at $-20^{\circ} \mathrm{C}$. In order to reduce or exclude infection risk the animals were deep-frozen at $-80^{\circ} \mathrm{C}$ for at least 7 days before necropsy (Eckert et al., 2001). At necropsy the animals were sexed and divided into two age classes (juveniles, adults). Age was determined by the extent of teeth abrasion: foxes younger than circa 8 months were considered as juveniles (J) and older ones as adults (A). The small intestines were isolated and ligatured at both ends, wrapped in plastic bags and frozen at $-20{ }^{\circ} \mathrm{C}$ until examination. The intestinal scraping technique was used to detect E. multilocularis (Eckert et al., 2001; Delplazes and Eckert, 1996). The small intestine was placed on a plastic sheet, divided in five equal parts and each part was opened in full length with scissors. After removal of coarse material (stones, bones) and large parasites (nematodes, Taenia spp.) deep mucosal scrapings were made using microscopic slides. The mucosal material adhering to the slide was transferred to a plastic Petri dish and squashed to a thin layer by means of pressure on the slide. A mucosal scraping was taken at the proximal, middle and posterior third of each of the five parts of the small intestine (i.e. a total of 15 scrapings per intestine). The mucosal squashes were then examined under a stereoscopic microscope. The adult tapeworms were identified and estimates of the infection rates per intestine were grouped as follows: low, 1-50 worms; medium, 51-100 worms; high, 101-1000 worms; very high, $>1001$ worms.

Data on the occurrence and density of foxes in Flanders in 1981 and 1995 were provided by the Ministry of the Flemish Community. The distribution data were cartographically processed with GIS ArcView software (1996).

\section{Results}

Because of varying cooperation of hunting and nature associations, the map with the geographic spread of the analysed Red foxes shows that the fox sampling is spatially irregular. Therefore, the parasitological results will not be discussed according to different natural regions in northern Belgium.

The parasitological analysis revealed that two adult male and two adult female foxes $(1.7 \%)$ were infected with adult tapeworms. The origins of the infested foxes were Kalmthout, Geraardsbergen, Halle and Edingen (Fig. 1). The four infected foxes harboured medium to very high parasitic burdens (Table 1).

The cartographically processed distribution data of the Red fox in northern Belgium showed a spectacular increase of this predator's geographic range during the last two decades (Fig. 2).

Table 1

Adult Red foxes ( $V$. vulpes) infected with E. multilocularis in northern Belgium

\begin{tabular}{lllc}
\hline Locality & Sex & Weight $(\mathrm{kg})$ & Burden E. multilocularis \\
\hline Geraardsbergen & $\delta$ & 6.90 & $101-1000$ \\
Edingen & $\wp$ & 7.25 & $>1001$ \\
Halle & $\delta$ & 7.25 & $101-1000$ \\
Kalmthout & $\wp$ & 7.75 & $51-100$ \\
\hline
\end{tabular}




\section{Echinococcus multilocularis in Red foxes in northern Belgium}

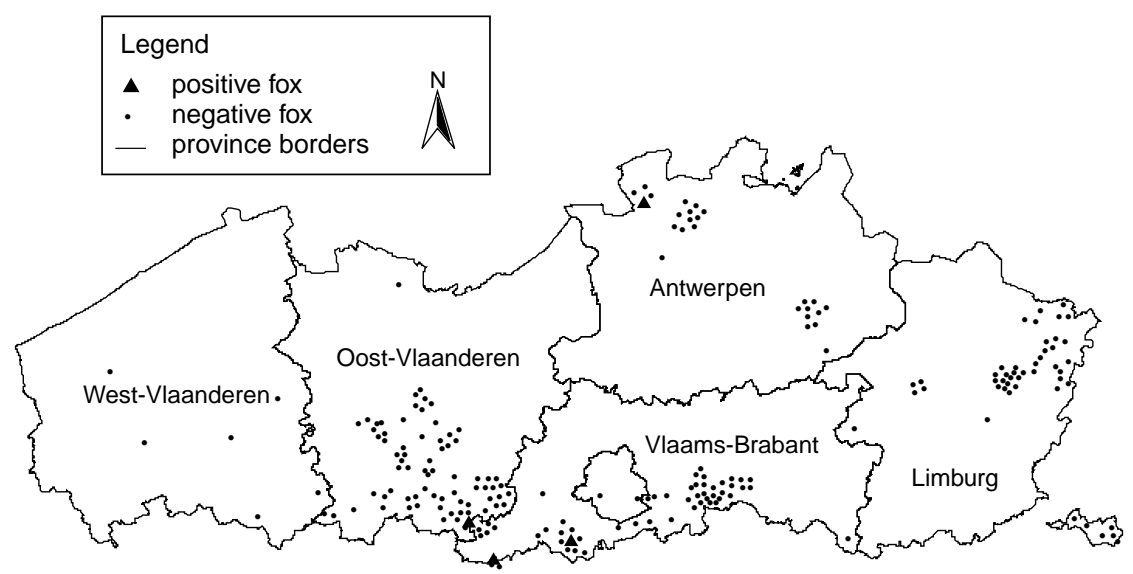

Fig. 1. Geographic spread of the 237 analysed Red foxes ( $V$. vulpes) in northern Belgium and prevalence of $E$. multilocularis.

\section{Discussion}

As in most European countries (Romig et al., 1999), a spectacular increase in the distribution and density of the Red fox (V. vulpes) occurred in northern Belgium over the last two decades. A comparison of the distribution maps from 1981 to 1995 (Fig. 2) illustrates that in the early 1980s foxes were only present in the middle and southern part of the provinces Vlaams-Brabant, Limburg and the northern and eastern part of Antwerpen. In 15 years time the fox population density increased over its 1981 range and the whole territory of northern Belgium was colonised. The legal restriction on fox hunting, reduced mortality due to changes in rabies control programs (use of vaccine baits), nature conservation measures and the opportunistic behaviour (adaptation) of the fox are all plausible reasons for its explosive population growth. Considering the rapid increase in numbers and the geographical spread of the Red fox in northern Belgium, and given the presence of the parasite in southern Belgium and surrounding countries (Germany, France, The Netherlands), the occurrence of E. multilocularis in northern Belgium could be expected. It is important to notice that the presence of four (4/237) infected foxes in northern Belgium cannot be interpreted as an estimate of prevalence. Heterogeneous spatial distribution patterns appear to be a particular epidemiological feature of the parasite (Tackmann et al., 1998) and this implies that estimates of prevalence in suspected low or moderate endemic regions should be carried out in small regional units (maximal area of $500 \mathrm{~km}^{2}$; Tackmann et al., 1998) with sufficient sampling effort.

As historical data are lacking it is impossible to determine whether the occurrence of $E$. multilocularis reflects a recent range extension of the parasite or whether it is just the first identification in a previously unnoticed infected area. However, given the high prevalence of the parasite in southern Belgium (Brochier et al., 1992; Losson et al., 1997; Losson et al., 
(a) Distribution of the Red fox in northern Belgium in 1981

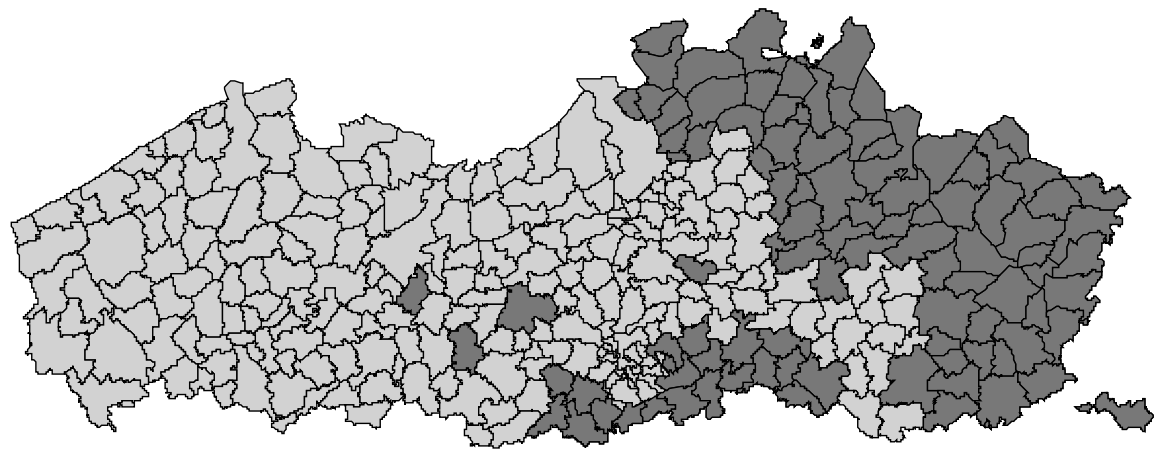

Legend

$\square$ Red fox present in municipality $\square$ Red fox absent in municipality $\square$ no data on occurrence of Red fox

(b) Distribution of the Red fox in northern Belgium in 1995

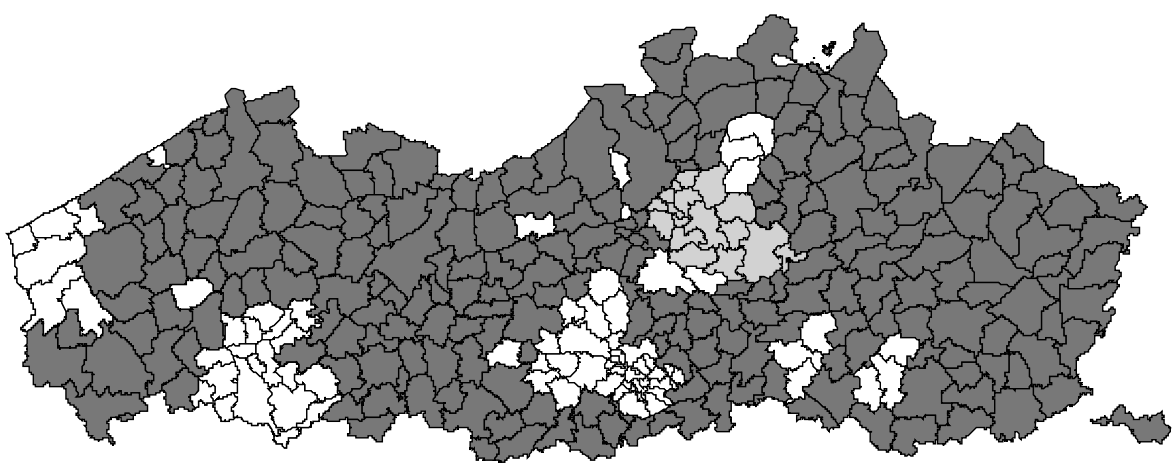

Fig. 2. Distribution of the Red fox (V. vulpes) in northern Belgium in 1981 (a) and 1995 (b).

unpublished data), the relative small distances between southern and northern Belgium and the high mobility of Red foxes, the finding of three infected foxes in the south of the study area (i.e. middle of Belgium: Geraardsbergen, Halle and Edingen) can be assumed to reflect the presence of a sylvatic cycle of E. multilocularis. Concerning the positive fox in the north of the province of Antwerpen, there is no endemic region in the surroundings that overlap, and at this point no conclusions can be made whether this is a single case due to a recent introduction of E. multilocularis in this area or the first indication of a sylvatic cycle of the parasite. A recent study in The Netherlands (van der Giessen et al., 1999) showed a similarly patchy distribution of positive foxes near the southeastern border of the country. The patchy 
distribution of few infected foxes with E. multilocularis in the north of Belgium and the southeast of The Netherlands may be to be due to a recent range extension of the parasite in these areas. To validate these hypotheses, we recommend that a study be conducted to measure the prevalence of this parasite in the final and intermediate hosts in the two areas in northern Belgium where infection of Red foxes with $E$. multilocularis has been detected.

Considering the extremely high human population density in northern Belgium, the spectacular increase of the Red fox population in this region and the presence of this potentially highly pathogenic zoonotic parasite, an intensive monitoring and control programme is desirable.

\section{Acknowledgements}

This research was possible thanks to a grant from F.W.O. Vlaanderen to Muriel Vervaeke, and the project was supported financially by the Ministry of the Flemish Community (A.M.I.N.A.L.-BG/5/1995) and the European Commission (FAIR CT97-3515). The authors wish to acknowledge the cooperation of several hunting and nature associations for providing dead foxes, Prof. Dr. Weyns of the Veterinary Department of the University of Antwerp for the use of his laboratory, and Sofie Thys for technical assistance during the autopsies.

\section{References}

Brochier, B., Coppens, P., Losson, B., Aubert, M.F.A., Bauduin, B., Barrat, M.J., Costy, F., Peharpre, D., Pouplard, L., Pastoret, P.P., 1992. Enquête sur l'infestation du Renard roux (Vulpes vulpes) par Echinococcus multilocularis en Province de Luxembourg (Belgique). Ann. Med. Vet. 136, 497-501.

Delbecque, K., Detry, O., Hayette, M.P., Jeukens, T., Delvenne, P., Hardy, N., Delwaide, J., Demonty, J., Boverie, J., Demol, P., Hauwaert, C., Honore, P., Boniver, J., Jacquet, N., 2002. A case of hepatic alveolar echinococcosis contracted in Belgium. Acta Gastro-Ent. Belg. 65, 55-60.

Delplazes, P., Eckert, J., 1996. Diagnosis of the Echinococcus multilocularis infection in final hosts. Appl. Parasitol. 37, 245-252.

Dubinsky, P., Svobodova, V., Turcekova, L., Literak, I., Martinek, K., Reiterova, K., Kolarova, L., Klimes, J., Mrlik, V., 1999. Echinococcus multilocularis in Slovak Republic: the first record in Red foxes (Vulpes vulpes). Helminthologia 36, 105-110.

Eckert, J., Conraths, F.J., Tackmann, K., 2000. Echinococcosis: an emerging or re-emerging zoonosis? Int. J. Parasitol. 30, 1283-1294.

Eckert, J., Gemmell, M.A., Meslin, F.-X., Pawlowski, Z.S. (Eds.), 2001. WHO/OIE Manual on Echinococcosis in Humans and Animals: A Public Health Problem of Global Concern. World Organisation for Animal Health, France, 265 pp.

Eskens, U., 1997. Zum vorkommen von Echinococcus multilocularis bei Rotfüchsen im Einzugsgebiet des Staatlichen Medizinal-, Lebensmittel- und Veterinäruntersuchungsamts mittelhesen. Z. Jagdwiss. 43, 154-165.

Kolarova, L., 1999. Echinococcus multilocularis: new epidemiological insights in Central and Eastern Europe. Helminthologia 36, 193-200.

Kolarova, L., Pavlasek, I., Chalupsky, J., 1996. Echinococcus multilocularis (Leuckart, 1863) in the Czech Republic. Helminthologia 33, 59-65.

Losson, B., Mignon, B., Brochier, B., Bauduin, B., Pastoret, P.P., 1997. Infestation du Renard roux (Vulpes vulpes) par Echinococcus multilocularis dans la Province de Luxembourg (Belgique): résultats de l'enquête effectuée entre 1993 et 1995. Ann. Med. Vet. 141, 149-153. 
Lucius, R., Bilger, B., 1995. Echinococcus multilocularis in Germany: increased awareness or spreading of a parasite? Parasitol. Today 11, 430-434.

Petavy, A.F., Deblock, S., Walbaum, S., 1991. Life cycles of Echinococcus multilocularis in relation to human infection. J. Parasitol. 77, 133-137.

Petavy, A.F., Tenora, F., Deblock, S., Sergent, V., 2000. Echinococcus multilocularis in domestic cats in France, a potential risk factor for alveolar hydatid disease contamination in humans. Vet. Parasitol. 87, 151-156.

Romig, T., Bilger, B., Dinkel, A., Merli, M., Mackenstedt, U., 1999. Echinococcus multilocularis in animal hosts: new data from western Europe. Helminthologia 36, 185-191.

Tackmann, K., Löschner, U., Mix, H., Staubach, C., Thulke, H.-H., Conraths, F.J., 1998. Spatial distribution patterns of Echinococcus multilocularis (Leuckert, 1863) (Cestoda, Cyclophyllidea, Taeniidae) among Red foxes in an endemic focus in Brandenburg, Germany. Epidemiol. Infect. 120, 101-109.

Thompson, R.C.A., Lymbery, A.J. (Eds.), 1995. Echinococcus and Hydatid Disease. CAB International, Wallingford, UK, $477 \mathrm{pp}$.

van der Giessen, J.W.B., Borgsteede, F.H.M., 2002. Echinococcus multilocularis: the prevalence of the fox tapeworm with possible large consequences for humans. Tijdschr. Diergeneeskd. 127, 318-320.

van der Giessen, J.W.B., Rombout, Y.B., Franchimont, J.H., Limper, L.P., Homan, W.L., 1999. Detection of Echinococcus multilocularis in foxes in The Netherlands. Vet. Parasitol. 82, 49-57.

van der Giessen, J.W.B., Rombout, Y.B., Evers, E.G., Arends, B., van der Veen, A., 2001. The prevalence of Echinococcus multilocularis in foxes in Groningen 1998-2000. Report No. 258725003. Rijksinstituut voor Volksgezondheid en Milieu, Bilthoven. 